paediatricians, rheumatologists, orthopaedic surgeons, and others faced with the conundrums in diagnosis and management which present in this field.

\section{Slide Interpretation in Postgraduate Medicine}

By P. S. Parfrey and J. Cunningham. Pp. 156, illustrated. Oxford University Press, Oxford, Melbourne, Delhi, 1981. £8.95.

Visual display is taking a greater part in many examinations including Membership to the Royal College of Physicians, and postgraduates studying for these examinations will appreciate this book. Rightly, the authors have directed the level at Membership standard and have included some questions that are more difficult. Having said that, some of the examples are disappointing. Thus, questions $2 \cdot 3,2 \cdot 6$, and 3.5: one gets the impression that the authors constructed questions around inadequate slide illustrations, which is an unsatisfactory approach. It is useful to have questions on more esoteric aspects of medicine and also important to have classical illustrations of these problems rather than slides that can be interpreted in many ways. On a more positive note, many of the slides illustrate points very well, reproduction is quite good and the authors cover a wide range of problems. The answers are of necessity short but usually have one or two pertinent points which are useful. Although a bibliography is given at the end of the book, many of the references are to large text books and one wonders whether recent reviews might not have been more useful. On the whole, this book is a useful addition to the armamentarium of the membership candidate and will well accepted in postgraduate circles.

Topics in Gastroenterology, Vol. 8.

Edited by S. C. Truelove and H. J. Kennedy. Pp. xi $+\overline{3} \bar{q}$, illustrated. Blackwell Scientific Publications, OxfoEd, London, Edinburgh, Boston and Melbourne, $198 \overline{80}$. $£ 16.00$.

In January 1973 a Postgraduate Gastroenterology Course was held in Oxford and its success clearly reflected the care and thought of the prime mover, Sidney Truelove. The bogt, based on the lectures given at the course, was published soon afterwards and was received with equal success. That was the first Topics in Gastroenterology and this book is the eigh in line of a series which has become firmly established as a useful review of certain current gastroenterological topes. Although, as in this volume, aspects of gastroenterology associated with the work of the Oxford group are given prominence, recent advances and controversial issues in the general gut field are covered. There are 4 sections in this edition, 2 of which are devoted to inflammatory bowel disease, one to parenteral feeding and one to miscellaneogs topics including antibiotic-associated colitis and the surgical management of severe obesity. It was refreshing to red contributions from an ileostomist and stoma therapist. Furthermore its value is not restricted to gastroenterologișts and I refer particularly to the articles on parenteral feeding. The book is easily and quickly read, has an even style and can be recommended as being thoroughly useful. 